\title{
O PROBLEMA DA AVALIAÇÃO DAS HABILIDADES SOCIOEMOCIONAIS COMO POLÍTICA PÚBLICA: EXPLICITANDO CONTROVÉRSIAS E ARGUMENTOS
}

\author{
Ana Luiza Bustamante Smolka* \\ Adriana Lia Friszman de Laplane* \\ Lavinia Lopes Salomáo Magiolino* \\ DÉbora DaINEZ*
}

\begin{abstract}
RESUMO: Este texto analisa a proposta de avaliação de competências sócioemocionais - Social and Emotional Non-cognitive Nationwide Assessment (SENNA) - que vem sendo disseminada como consensual e inovadora no Brasil. O artigo explicita controvérsias; examina os fundamentos do construto Big Five que sustenta a proposta; discute a utilização da análise fatorial como base para o estudo da personalidade; problematiza a separação das dimensôes cognitiva e emocional e contesta a redução da personalidade a poucos traços analisáveis separadamente. Diante dos riscos de simplificar a complexidade do desenvolvimento humano e de estigmatizar alunos que não demonstrem as competências estipuladas como desejáveis, questiona-se a pertinência de se assumir tal proposta como política pública.
\end{abstract}

Palavras-chave: Avaliação; Personalidade; Desenvolvimento humano; Competências socioemocionais; Política pública.

\section{THE SOCIOEMOTIONAL HABILITIES ASSESSMENT AS PUBLIC POLICY: MAKING EXPLICIT CONTROVERSIES AND ARGUMENTS}

ABSTRACT: This article analyzes the Social and Emotional Non-cognitive Nationwide Assessment (SENNA) proposal, which has been disseminated as consensual and innovative in Brazil. The paper expounds some of its controversies; examines the foundations of the Big Five construct that supports the proposal; discusses the use of factor analysis as a basis for the study of personality; questions the separation of the cognitive and emotional dimensions and disputes the reduction of personality to a few traits that could be separately analyzable. Given the risks of simplifying the complexity of human development and of stigmatizing students

\footnotetext{
* Universidade Estadual de Campinas, Faculdade de Educação, Campinas, SP., Brasil. E-mail de contato: asmolka@unicamp.br.

** Universidade Estadual de Campinas, Faculdade de Ciências Médicas, Campinas, SP., Brasil. E-mail de contato: adrifri@fcm.unicamp.br.
} 
who do not demonstrate the competencies stipulated as desirable, we call into question the pertinence of taking such a proposal as a public policy.

Keywords: Evaluation; Personality; Human development; Socioemotional competencies; Public policies.

\section{LE PROBLÈME DE L'ÉVALUATION DES COMPÉTENCES SOCIO-ÉMOTIONNELLES EN TANT QUE POLITIQUE PUBLIQUE: CONTROVERSES ET ARGUMENTS}

RÉSUMÉ: Cet article analyse la proposition d'évaluation des compétences socio-émotionnelles - Social and Emotional Non-cognitive Nationwide Assessment (SENNA) - qui a été diffusée comme consensuelle et innovante au Brésil. L'article a pour but d'expliciter des controverses; il examine les fondements du construct Big Five qui soutient la proposition; il discute l'utilisation de l'analyse factorielle comme base de l'étude de la personnalité; il met en question la séparation des dimensions cognitives et émotionnelles et la réduction de quelques traits de personnalité qui peuvent être séparément analysés. Compte tenu des risques de simplifier la complexité du développement humain et de stigmatiser les élèves qui ne démontrent pas les compétences stipulées comme souhaitables, on s'interroge sur la pertinence de prendre une telle proposition en tant que politique publique.

Mots-clés: Evaluation; Personnalité; Dévelopement humain; Compétences socio-émotionnelles; Politiques publiques.

\section{Introdução}

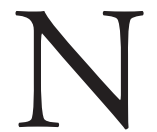

as últimas décadas, as políticas públicas, pautadas pela ideia de que é necessário avaliar para identificar o sucesso/fracasso e o andamento de projetos, programas, sistemas - de saúde, educação e outros - têm adotado modelos de avaliação instituídos em outros países, alguns propostos em âmbito mundial. Dentre estes, podemos mencionar o Pisa - Programme for International Student Assessment -, como uma das avaliaçóes de larga escala, que tem constituído tema de acirrados debates (FREITAS, 2002, 2004; ROCHEX, 2008, 2012; CLACSO, 2014), reascendendo polêmicas sobre o desenvolvimento e a aprendizagem das crianças, os objetivos e os processos de escolarização e os procedimentos de avaliação na contemporaneidade.

Uma das recentes iniciativas de avaliação no Brasil é a impulsionada pelo Instituto Ayrton Senna, em parceria com a Organização para a Cooperação e Desenvolvimento Econômico (OCDE) e a Secretaria Estadual de Educação 
do Rio de Janeiro, que inclui a medição de competências socioemocionais em estudantes do $5^{\circ}$ ano do ensino fundamental ao 30 ano do ensino médio, com vistas a transformar essa medição em política pública de avaliação e em abordagem educacional a ser adotada no país.

De uma maneira geral, políticas e práticas de educação se baseiam em concepçóes que se nutrem das teorias gestadas nos diferentes campos de conhecimento: as teorias de desenvolvimento humano, advindas da psicologia, e as teorias da educação que provêm da filosofia e da pedagogia, da sociologia e da antropologia, aliadas ao conhecimento produzido em áreas como biologia, neurociência e linguística que fornecem as bases sobre as quais se cria conhecimento que subsidia a formação dos educadores, a formulação de políticas e a fundamentação de práticas de ensino.

Estudar, portanto, o desenvolvimento e a aprendizagem humana, bem como suas condiçôes de realização e possibilidades de avaliação é tarefa, sem dúvida, importante e necessária para compreender de que forma os equipamentos sociais que colaboram para formar as novas geraçôes podem intervir e ser melhor sucedidos na concretização de seus objetivos e na consecução das suas metas. Contudo, a adoção de estratégias de investigação e avaliação requer um exame cuidadoso dos seus pressupostos e implicaçóes para a educação. A proposta denominada Social and Emotional Non-cognitive Nationwide Assessment (SENNA), que vem se disseminando como inédita e inovadora por seus proponentes e adeptos, se insere no escopo dessas estratégias e merece ser analisada com atenção. Quais as teorias e concepções que a embasam?

O Relatório intitulado: Desenvolvimento socioemocional e aprendizado escolar: Uma proposta de mensuração para apoiar políticas públicas, de autoria de Daniel Santos e Ricardo Primi (2014), apresenta os resultados preliminares do projeto piloto acima mencionado, discorrendo sobre as pesquisas científicas e as evidências empíricas que o sustentam, e fazendo referência a um "[...] amplo conjunto de instrumentos psicométricos consagrados na literatura internacional [...]”. (SANTOS; PRIMI, 2014, p. 12) Os autores esclarecem que o primeiro grande objetivo do Projeto foi construir um instrumento ao mesmo tempo "economicamente viável para aplicação em larga escala" e "cientificamente robusto para subsidiar pesquisas acadêmicas na área”.

Os autores se referem a pesquisas conduzidas por economistas, psicólogos e educadores; falam da "visão rigorosa" dos estudos e do "impacto positivo comprovado pela evidência científica"; ressaltam a relevância do desenvolvimento socioemocional para o aprendizado e admitem a importância da escola que, mesmo náo estando preparada atualmente para as necessidades dos novos tempos, ainda assim "[...] contribui para o desenvolvimento de atributos socioemocionais associados ao sucesso [...].”. (SANTOS; PRIMI, 2014, p.15) 
Afirmam ainda que:

Nas últimas décadas, manifestou-se entre os psicólogos um consenso de que a maneira mais eficaz de analisar a personalidade humana consiste em observá-la em cinco dimensôes, conhecidas como os Cinco Grandes Fatores: Abertura a Novas Experiências, Extroversão, Amabilidade, Conscienciosidade e Estabilidade Emocional. Os Big Five são construtos latentes obtidos por análise fatorial realizada sobre respostas de amplos questionários com perguntas diversificadas sobre comportamentos representativos de todas as características de personalidade que um indivíduo poderia ter. Quando aplicados a pessoas de diferentes culturas e em diferentes momentos do tempo, esses questionários demonstraram ter a mesma estrutura fatorial latente, dando origem à hipótese de que os traços de personalidade dos seres humanos se agrupariam efetivamente em torno de cinco grandes domínios. (SANTOS; PRIMI, 2014, p. 17)

O Relatório apela para um "rigor científico" e proclama um "consenso" que, na realidade, se mostram como pontos altamente questionáveis, sobretudo, com relação a alguns aspectos ou concepções que fundamentam a proposta, referentes à noção de personalidade e à concepção de desenvolvimento nela implicada.

Com relação a isso, um problema, explicitado claramente no título da proposta, é que se descartam, por princípio, as intrínsecas relaçóes entre emoção e cognição. Enquanto, no campo mais abrangente das ciências, da Neurologia à Sociologia, os esforços vão no sentido de buscar novas formas de compreensão e de investigação dessas intrínsecas relações, o pressuposto reiterado na avaliação é que é possível tratar de emoção e de personalidade dispensando ou alijando-a da dimensão cognitiva (Non-cognitive Assessment).

Diante dessas dificuldades, nossa proposta aqui é explicitar as controvérsias e trazer para o debate fundamentos, princípios e argumentos, visando a contribuir para a proposição de outras formas de atuação e tomadas de decisão no âmbito das políticas públicas.

\section{Sobre a questão da personalidade}

Na linha da divulgação de programas de impacto na educação, a Revista Época lançou, em setembro de 2013, uma reportagem: Caráter se aprende na escola, destacando os traços de personalidade que são decisivos para o bom desempenho escolar e o sucesso no trabalho, e propondo a preparação da escola para ensiná-los e avaliá-los. Características como a perseverança, o autocontrole, a 
extroversão, o protagonismo, a curiosidade e a cooperação são descritas e ressaltadas em depoimentos de estudantes que se destacaram na escola e na conquista do emprego desejado. A reportagem não faz referência ao SENNA, mas faz menção aos estudos dos economistas que defendem tais "habilidades não cognitivas" como traços de personalidade e "habilidades do século XXI".

Para melhor compreender como se configuram essas "habilidades náo cognitivas do século XXI" vale ampliar o escopo das indagações e procurar situar algumas das questóes que estavam em pauta nos séculos XIX e XX, colocando em realce, por exemplo, as preocupaçóes com as diferenças individuais e as variadas estratégias de conduta face às demandas de adaptação ao meio; o problema das motivaçôes que dirigem os comportamentos humanos; a questão da patologia, dentre outras. Em meio a essas preocupaçôes, eram diversos os modos de se conceber e abordar a personalidade: como estrutura, como sistema, como processo; como traços distintivos ou disposições estáveis; como tipos característicos ou conjunto de marcas individuais, que podem ser generalizáveis; como formaçóes dinâmicas em condiçôes concretas de desenvolvimento.

No âmbito da então emergente Psicanálise, Freud, Jung, Adler, Fromm, Erikson, foram autores que procuraram levar em conta os impactos - positivos, negativos, ou constitutivos - da história e da cultura na formação da personalidade, e cujas contribuições marcaram modos de pensar nesses séculos.

A novidade e a complexidade das elaboraçóes freudianas com relação à organização e funcionamento do aparelho psíquico, à energia e às instâncias psíquicas, às pulsóes de vida e de morte, à dinâmica afetiva, ao inconsciente, vão repercutir profundamente nas teorizaçóes em psicologia, ao mesmo tempo em que provocam contestaçóes e desdobramentos no interior da própria psicanálise. No que tange às incansáveis (re)consideraçóes de Freud a respeito das relaçóes e configuraçôes do Ego e do Id (FREUD, 1923/2006), a noção de identificação adquire relevância, principalmente em alguns de seus textos mais tardios. A identificação é concebida como a mais remota expressão de um laço emocional com outra pessoa. Pode-se admitir, assim, que o que se chama personalidade constitui-se e diferencia-se por uma série de identificações. (LAPLANCHE; PONTALIS, 1982) Freud analisa a ambivalência das identificaçóes com o pai, com o agressor, por exemplo, e explica, em sua discussão com Gustav Le Bon, a coesão das massas pelo processo de identificação com os outros. (FREUD, 1921/2013) Na clássica obra O Mal-estar na Civilizaçâo, Freud (1930/1992) problematiza as relaçóes do indivíduo com o meio social, opondo o desejo de felicidade individual às restriçôes da sociedade e imposições da civilização, admitindo, ao mesmo tempo, o inescapável dessa condição humana.

Orientando o seu interesse para os determinantes conscientes do comportamento e para o impacto da posição social ocupada pelo indivíduo no meio 
para a formação da personalidade, Adler $(1967,2003)$ se afasta da escola de Freud, ressaltando a ideia de que cada indivíduo se organiza em função da sua percepção subjetiva do mundo social, caracterizando, assim, maneiras específicas de ser. Adler $(1967,2003)$ argumenta que a personalidade precisa ser analisada não pela regressão ao passado, pelos traumas gerados na infância, mas na sua orientação para o futuro. Com isso, ele formula a ideia da "direção final da conduta e de objetivo futuro" a ser alcançado pelas forças individuais mobilizadas pela necessidade de acomodação ao meio e busca da superioridade ou completude, sendo que cada pessoa tem seu modo de "atingir a perfeição". (DAINEZ; SMOLKA, 2014)

Essas ideias podem ser identificadas também nos argumentos presentes na proposta de avaliação das competências socioemocionais que destacam a capacidade individual de superar os desafios, de modificar a situação social, de atingir benefícios próprios e alcançar o sucesso conforme um padrão ideal previsto, conformando a personalidade ao meio.

Dentre as teorias com grande repercussão no século $\mathrm{XX}$, podemos mencionar a de Erik Erikson, psiquiatra e psicanalista alemão que trabalhou com Anna Freud e que, embora parta do modelo da teoria freudiana, dela se distancia em vários pontos. Um desses, também criticado por Adler, é a explicação das experiências pelos traumas da infância, o que pressupóe um aspecto fixo e imutável da personalidade. Erikson contesta o modo como Freud considera as relaçóes indivíduo/meio, questiona o fato de se privilegiar os aspectos patológicos e defensivos da personalidade, e desloca o foco do desenvolvimento psicossexual para o problema da identidade nas relaçóes sociais. Reinterpretando os conceitos freudianos, amplia a noção de ego, analisando as crises prototípicas nas diferentes etapas do desenvolvimento. Elabora, assim, a conhecida Teoria do Desenvolvimento Psicossocial, ressaltando a importância da história e da cultura na formação da personalidade. (ERIKSON, 1976a; 1976b)

$\mathrm{Na}$ linha dos humanistas norte-americanos que apontavam a necessidade de examinar não só os piores, mas também os melhores atributos humanos, Carl Rogers teve expressão importante. Investindo nos estudos sobre a psicoterapia, o autor forjou a chamada Terapia Centrada na Pessoa. (ROGERS, 1961/1976) Posicionou-se contra a ideia de que o indivíduo é reprimido por forças inconscientes e que, portanto, há a possibilidade de mudança das formas de conduta pela consciência da ação. A personalidade é, assim, delineada pelo modo como o indivíduo percebe a situação e pelos esforços conscientes de tornar-se alguém melhor, moldando a própria vida. Evidencia-se como força motivadora da personalidade a forma de "atenção positiva incondicional" do outro em relação ao self, gerando condições de aceitação e auto-realização, que consiste na saúde psicológica.

Participando do humanismo norte-americano, com ideias marcadas fortemente pelo comportamentalismo, e em diálogo com Freud e Erikson, 
Gordon Allport elaborou sobre o conceito de "self", buscando o que há de mais essencial, ou proprium, na personalidade, e procurando meios de descrever aquilo que corresponderia ao que cada pessoa, mais centralmente, é. Na medida em que o self se desenvolve, certos traços ou disposiçóes pessoais vão também se desenvolvendo. Revisou centenas de termos e dedicou-se à construção de vários testes de personalidade. Especificou sete funçóes que tendem a surgir em determinados momentos na vida de um indivíduo (senso do corpo, auto-identidade, autoestima, auto-extensão, auto-imagem, elaboração racional e orientação pessoal ou senso de objetivo), chegando à definição de disposição pessoal como uma estrutura neuropsíquica generalizada (peculiar ao indivíduo), com a capacidade de tornar muitos estímulos funcionalmente equivalentes, e iniciar e guiar formas consistentes (equivalentes) de comportamento adaptativo e estilístico. (ALLPORT, 1937; 1965) A personalidade encontra-se, assim, relacionada a sistemas psicofísicos que determinam comportamentos e características de pensamento, sendo a pessoa orientada pela motivação de apresentar um desempenho cada vez melhor (mais adaptado) e a adquirir novas habilidades, aumentando o grau de competência. (ALLPORT; ODBERT, 1936)

Nessa tendência, assume-se que existem traços ou disposições comuns àqueles que participam de uma determinada sociedade, e esses podem ser reconhecidos, valorizados, nomeados e quantificados. Parte-se da hipótese lexical, em circulação desde os primeiros estudos de Francis Galton, pela qual se deduz que os traços de personalidade definidos como os mais relevantes para a vida das pessoas são codificados pela língua. A ideia é, portanto, que em uma determinada cultura há termos que possibilitam caracterizar seu povo.

Ao longo do século XX, a hipótese lexical inspirou o desenvolvimento de diversos modelos para o estudo da personalidade. Autores como Cattell (1946, 1965) e Eysenck (1970) foram alguns dos que produziram trabalhos precursores do modelo dos Big Five, desenvolvido na década de 1980 por McCrae e Costa (1989). Este pressupóe a possibilidade de uma personalidade replicável em diversos países e diferentes culturas, apresentando cinco variáveis universais: extroversão, agradabilidade, conscienciosidade, neuroticismo e abertura à experiência. Seus proponentes garantem que essa estrutura de personalidade é encontrada em uma ampla gama dos participantes do teste aplicado em diferentes culturas.

Nas interseções do behaviorismo social com a psicologia cognitiva, o trabalho contemporâneo de Albert Bandura também merece ser mencionado. Relacionando teorias da aprendizagem e teorias da personalidade e investigando as relaçóes entre as expectativas das pessoas com seus comportamentos, o psicólogo canadense propóe o conceito de "auto-eficácia” ao examinar o que as pessoas esperam fazer e como elas de fato executam o que se propóem a fazer. Seus estudos revelaram um padrão na interação entre os mapas mentais e desempenho comportamental que é conhecido como a "Curva de Bandura". (BANDURA, 2014) 
Uma das linhas atuais de pesquisa na Teoria Social Cognitiva (BANDURA; AZZI; POLYDORO, 2008) diz respeito a como as pessoas regulam suas motivações, seus pensamentos e estados afetivos através das crenças na eficácia pessoal e coletiva; outra linha examina os mecanismos de auto-regulação, respaldado por padróes internos e auto-influência no próprio desenvolvimento, adaptação e mudança.

As ideias de Bandura e o modelo dos Big Five, oriundo das posiçóes teóricas destacadas acima, integram o núcleo teórico que sustenta a proposta de avaliação das competências socioemocionais.

No entanto, é necessário ter em vista que outras linhas teóricas emergem e se potencializam também no século XX, dentre elas, a que se produz nas intersecções da psicanalise e do materialismo histórico-dialético. Erik Fromm é um de seus representantes mais conhecidos. Na busca de compreender o homem em sua existência social, Fromm $(1961,1963,1967,1970)$ ressalta em seus estudos a interdependencia dos fatores socioecônomicos, psicológicos e ideológicos. Concebe a personalidade como totalidade de qualidades herdadas geneticamente (refere-se ao temperamento) e adquiridas na experiência social da pessoa em dada sociedade (refere-se ao caráter), destacando a sua diversidade e dinamicidade. Considera que "[...] o ambiente nunca é exatamente o mesmo para duas pessoas, pois suas diferenças de constituição fazem-nas sentir de maneira mais ou menos distinta a influência desse ambiente [...].” (FROMM, 1961, p.62)

Como é passível de nota, o autor preocupa-se, sobretudo com os impactos da cultura na personalidade e, deste modo, considera o "conceito dinâmico do caráter" de Freud, mas, ao mesmo tempo, difere dessa posição por entender que a base do caráter em que está afirmada diz respeito aos variados tipos de organização da libido e não aos tipos especificos de relacionamento da pessoa com o mundo. (FROMM, 1961) Neste sentido, mesmo referindo-se a “traços de caráter", modo recorrente em sua época, Fromm (1961, 1963, 1967, 1970) argumenta sobre a impossibilidade de tratar isoladamente esses traços, ou de entendê-los como uma somatória, defendendo, assim, a organização total do caráter, a sua determinação nas condiçóes de vida e a sua função no processo social. É nesse último aspecto que Fromm $(1967,1970)$ se detém de forma intensa. Investindo na questão deixada em aberto por Marx e Engels, de como as bases econômicas se traduzem na superestrutura ideológica, formula o conceito de "caráter social" - núcleo da estrutura de caráter partilhada pela maioria dos membros de uma mesma cultura, de uma mesma sociedade que funciona de determinada forma.

O caráter social cumpre então o objetivo de manter e estabilizar o funcionamento, o modo de produção e as condiçóes objetivas de uma sociedade. Quer dizer, alguns traços são tidos como úteis para certo sistema socioeconômico, tornam-se valor/virtudes, e o indivíduo ao corresponder ao previsto, tem uma satisfação psicológica e um sucesso material. Entretanto, as análises do autor 
também nos levam a pensar naqueles que não se enquadram no padrão desejável, ou em quando o sistema socioeconômico não dá conta de atender e satisfazer as necessidades psicológicas, individuais, sociais que ele mesmo produz. A contribuição da obra de Fromm é justamente provocar a reflexão sobre como certo sistema socioeconômico determina um tipo de personalidade desejável, quando no seu interior deflagram-se diversas condiçóes concretas de vida que agem na formação do caráter individual.

Ao discutir sobre a sociedade moderna, o autor mostra como o modo de sentir e de pensar é condicionado pela orientação mercantil de uma determinada sociedade. "O próprio conhecimento torna-se uma mercadoria. [...]. O pensamento e o saber são sentidos como instrumentos para produzir resultados [...].”. (FROMM, 1961, p.75) E, esse modo de pensar, tem efeitos no sistema educacional, sendo que o objetivo da aprendizagem é reunir informações úteis para finalidades de mercado - valor de troca assegurado pelos conhecimentos. "Preocupamo-nos com o caráter do homem, não com o seu sucesso [...].”. (FROMM, 1961, p.84)

Isso nos leva a pensar nas competências e habilidades socioemocionais e a indagar sobre os valores sociais, econômicos que as definem e as sustentam, assim como nos seus modos e condições de produção social.

Outro autor que teoriza sobre a formação da personalidade e do caráter, com amplo conhecimento dos aspectos psicofisiológicos, levando em conta os aspectos socioculturais do desenvolvimento humano, e em diálogo com Freud e Marx, é o médico e pedagogo Henry Wallon. Sublinhando a função do outro na relação individuo/meio social, Wallon propóe analisar a criança em seu contexto de vida e focaliza o processo de fusão e diferenciação da criança em relação àqueles que a cercam. Wallon (1979) argumenta sobre uma psicogênese da pessoa em sua complexidade e defende a impossibilidade de isolar um único aspecto no estudo da formação do homem, buscando comtemplar vários campos funcionais: a afetividade, a motricidade, a inteligência.

$\mathrm{Na}$ obra As origens do caráter na criança, Wallon relata de maneira minuciosa e detalhada a função e o desenvolvimento das emoções e a elaboração do caráter, mediante a sensibilidade da criança à presença do Outro que vai marcar o processo de constituição de sua personalidade. A explicação do processo de elaboração do caráter e constituição da personalidade repousa, para o autor, num complexo indissociável que abarca não apenas disposiçốes dos sujeitos - sejam estas neurofisiológicas, psíquicas ou biológicas - mas determinadas situaçóes sociais .(WALLON, 1934/1995) Para o autor, o caráter pode ser compreendido em torno do que compóe uma "espécie de índice individual" (WALLON, 1934/1995, p. 26) dos modos de agir e reagir do sujeito, uma marca que se torna mais estável embora não seja estática - no campo de uma personalidade geneticamente social e 
constituída na integração e alternância dos diferentes campos funcionais ao longo do processo de desenvolvimento.

Esse modo de conceber a formação da personalidade considera a passagem de uma afetividade impulsiva para uma afetividade que incorpora os recursos intelectuais e simbólicos socialmente produzidos. Os sentimentos tornam-se, assim, elaborados no plano cognitivo, o que implica um conflituoso movimento de identificação/oposição eu-outro na constituição da personalidade e afirmação do eu. Nesse processo de constituição, as emoçôes tornam-se ponto de partida da consciência e da personalidade por intermédio das ações do grupo social, pelas quais elas se fundem com os instrumentos intelectuais recebidos, podendo realizar generalizaçóes necessárias ao conhecimento das coisas e de si. A relação com o outro é ao mesmo tempo recurso, meio, motivo e condição do desenvolvimento e das açôes do sujeito individual.

Essa posição se aproxima da perspectiva histórico-cultural (VIGOTSKI, 1995, 1996, 2000, 2006; LEONTIEV, 1984) que vem impactando fortemente os estudos do desenvolvimento humano no âmbito nacional e internacional, e na qual se considera a dinâmica social de realização do desenvolvimento e a personalidade em processo de formação e mudança. Dessa perspectiva, o amadurecimento orgânico não se faz independente das relações sociais. Os processos psicológicos, compreendidos em sua dimensão histórica e cultural, são (trans)formados pela atividade do próprio homem em uma rede de relaçóes. A hipótese da plasticidade cerebral é ressaltada: o cérebro humano apresenta modos flexíveis e específicos de interação e constituição em resposta a objetivos produzidos socialmente e pessoalmente apropriados.

Novas formas de atividade psicológica se produzem a partir de determinadas situaçóes sociais de desenvolvimento (VIGOTSKI, 1996; LEONTIEV, 1984; VIGOTSKI; LURIA; LEONTIEV, 1988), que implicam mudanças psíquicas e sociais, as quais afetam a estrutura da personalidade e sua atividade como um todo. Ou seja, ressalta-se a integralidade do desenvolvimento, a unidade das dimensóes orgânicas e psíquica, social e individual, e o fato de que, no processo de desenvolvimento, não se modificam aspectos isolados da personalidade da criança, mas essa se reestrutura como um todo complexo. Nessa teorização, a forma inata, estática e fragmentada de se conceber a personalidade, a partir de traços e características isoladas, é fortemente colocada em questão.

Argumentando que o caráter é o "cunho social" da personalidade, Vigotski (2006) aponta para a orientação prospectiva do desenvolvimento, a direção futura do comportamento humano. Mobiliza a ideia de "reflexo objetivo" de I. Pavlov para mostrar que a orientação da conduta a um objetivo é parte da condição da vida, e também menciona a teoria de Adler sobre a orientação final do comportamento que está relacionado com a posição social ocupada pelo indivíduo 
no seu meio de existência. Nesse diálogo de Vigotski (2006) com os seus contemporâneos, podemos problematizar o modo de se conceber a ideia de objetivo que não é meramente um reflexo a certo estímulo externo, tampouco uma intenção individual; mas uma criação coletiva atravessada por exigências definidas e produzidas pelo grupo social, e que afetam o curso do desenvolvimento do indivíduo, impactam o funcionamento psicológico, mobilizam o funcionamento cerebral e orientam os rumos da (trans)formação da personalidade.

A compreensão da personalidade nesta perspectiva está, portanto, relacionada ao modo de conceber a sociogênese do desenvolvimento humano, a formação social dos processos psicológicos e a interrelação das funçóes psíquicas.

Outra das fecundas teorias contemporâneas, cujas raízes também se encontram no pragmatismo norte-americano, mais especialmente, nas elaboraçóes de George Mead (1934/1962), e no interacionismo simbólico de Erwing Goffman (1959/1985, 1963/1988) é a chamada Positioning Theory. (DAVIES E HARRÉ, 1990; HARRÉ, 2004) Tal teoria assume a importância das interaçóes e das práticas discursivas na constituição do self, que não é unívoco e imutável, pelo contrário, se constitui na diversidade das posições assumidas nas relaçôes sociais e conversacionais. Essa teoria, de caráter essencialmente relacional, considera que as pessoas falam e agem em situaçóes específicas e de determinadas posiçóes sociais, trazendo as marcas de sua história subjetiva, posicionando-se imaginariamente em relação aos outros e sendo por eles também posicionados. Nesse jogo de relaçóes e posiçôes, o self se mostra múltiplo e conflituoso. É nessa dinâmica interacional discursiva, na participação ativa nas práticas sociais e graças à linguagem, que as pessoas podem desenvolver um "senso de si" e de "pertença", (re)conhecendo-se como membros de diversos grupos ou comunidades.

Apresentando fecundas aproximaçóes com a Positioning Theory e compartilhando seus pressupostos - pragmatismo norte-americano de W. James e G. Mead, articulado a contribuições de Vigotski e Bakhtin na corrente histórico cultural - a Dialogical Self Theory (HERMANS; HERMANS-KONOPKA, 2010) se propóe a aprofundar o estudo e a compreensão da riqueza experiencial e das qualidades emocionais do self em intima conexão com os processos intersubjetivos.

$\mathrm{O}$ que se pode depreender do acima exposto, mesmo que tão sumariamente, é que há uma ampla gama de estudos e tendências, no que se refere às teorias e pesquisas sobre personalidade, e que na diversidade das contribuiçóes, existem sim, pontos de proximidade e/ou concordância. No entanto, uma análise das distintas elaboraçôes aponta para importantes e significativas controvérsias. Não há portanto, consenso, em relação à natureza e modos de constituição da personalidade humana. Nesse contexto, o modelo que elege os Big Five como os traços fundamentais da personalidade está longe de ser consensual e inovador. 


\section{Projeto "Desenvolvimento socioemocional e aprendizado escolar": o modelo e o instrumento de avaliação em discussão}

Os relatores do projeto piloto (SANTOS; PRIMI, 2014) comentam sobre programas considerados bem-sucedidos, fazem referência aos instrumentos selecionados, argumentam sobre as evidências científicas, os critérios de relevância, os resultados das avaliaçóes realizadas anteriormente. Falam da consulta a especialistas em sistemas educacionais, explicitam os procedimentos de composição do instrumento, justificam as escolhas e a utilização do modelo que assumem.

No entanto, vários são os pesquisadores que se contrapóem explicitamente ao fundamento do estudo: a abordagem dos Big Five. Como vimos, essa abordagem, apesar de ser apresentada como consenso no campo da psicologia da personalidade, desperta muitas críticas na comunidade científica. Autores como Block (1995a, 1995b, 2001, 2010) e Boyle (1997) apresentaram argumentos contrários ao uso da abordagem fatorial que originou os agrupamentos que decorreram da síntese dos cinco fatores que descreveriam a estrutura da personalidade humana: abertura a novas experiências, extroversão, amabilidade, ou afabilidade, conscienciosidade e estabilidade emocional.

Em vários de seus textos, Block se manifesta francamente contrário à utilização desse construto - Big Five - como base para a elaboração de instrumentos de medida para avaliar o desenvolvimento de crianças em formação e critica estudos que tentaram essa via.

Boyle (2008) descreve a personalidade como mutável, o que contradiz a ideia de um modelo que identifique traços (os quais pressupóem estabilidade). Boyle advoga por um modelo dinâmico que permita incluir as mudanças de personalidade decorrentes da aprendizagem. Os trabalhos de Cattell, Boyle e Chant, 2002; Fraley e Roberts, 2005; Roberts, Walton, Viechtbauer, 2006a, 2006b, aportam evidências em relação ao caráter mutável da personalidade. Embora haja consenso entre os pesquisadores em relação à ocorrência de mudanças na personalidade ao longo da vida, esta é atribuída pelos pesquisadores que trabalham com os Big Five a fatores genéticos e maturacionais. De acordo com eles, as influências genéticas se manifestam em diferentes momentos da vida, de formas distintas na personalidade. (McCRAE et. al., 2000) Analisando esses estudos, Helson e seus colaboradores concluem que as mudanças registradas durante a existência do indivíduo podem ser manifestaçóes de aspectos gerais da aprendizagem social, produto da experiência. Mas, essa interpretação depende da compreensão da mudança de personalidade como um processo complexo, afetado por múltiplos fatores, que não se reduzem aos genéticos. (HELSON et al., 2002)

O caráter estático e determinista da descrição também é criticado por inviabilizar a integração e interrelação complexa e não linear hoje aceita pelas 
concepçóes que destacam o papel da cultura no processo de desenvolvimento humano.

Outro aspecto que desperta controvérsias é o a-teoricismo da abordagem. Já na década de 1990, Briggs (1992) e Eysenck (1993) levantam essa questão. Briggs argumenta sobre a falta de especificidade dos Big Five, que seria decorrente do seu empirismo. Block (2010) radicaliza ao afirmar que a análise fatorial deveria servir para confirmar e iluminar sugestôes, mas estas devem proceder de consideraçóes teóricas e epistemológicas e não de uma técnica estatística. A proliferação de modelos que admitem diferentes números de fatores, traços e dimensóes, parece confirmar a falta de consenso em relação a quais e quantos seriam os fatores capazes de descrever a personalidade humana. (EYSENCK, 1992, 1997; PERVIN, 1994; McADAMS, 1992) A modo de exemplo, o modelo de Zuckerman e Kuhlman (ZUCKERMAN, 2002) se apresenta como uma alternativa na qual três dos fatores coincidem em grande parte com o modelo de Costa e McRae (1992), um fator apresenta coincidência apenas parcial e o quinto fator difere totalmente. Boyle (2008) levanta a questão de que apesar da sua aceitação como ferramenta para tratar dados, apenas duas das dimensóes dos Big Five (a Extroversão e o Neuroticismo) estão presentes nos modelos de personalidade existentes. A interpretação dos outros três permanece sujeita a muitas controvérsias e questionamentos.

A validade do construto também foi questionada a partir do fato de que cada uma das suas dimensóes envolve um grande subconjunto de determinantes genéticos e ambientais. (JANG et al., 2002) Além disso, outros estudos como o de Toomela (2003) apontaram dificuldades na sua utilização, ao revelar, por exemplo, que uma estrutura coerente de personalidade emergia apenas em amostras cujos indivíduos apresentavam altas taxas de escolaridade formal, levantando dúvidas quanto ao suposto caráter genético das cinco dimensões.

A crítica de Block (2010) aponta aos próprios termos que compóem os Big Five, pela variedade de significados que carregam, pela ampla possibilidade de interpretaçóes a que se prestam e pela carga valorativa que incorporam. Os valores que perpassam os termos que supostamente descrevem a personalidade de modo neutral constituem, de fato, um grande problema: não se pode descartar uma eventual dificuldade dos indivíduos respondentes para identificar-se, no caso da utilização de instrumentos autodescritivos, como portadores de características socialmente não desejadas, como, por exemplo: não ser amável, não ser disciplinado ou organizado etc. Nesse sentido e apesar da sua popularidade, os Big Five têm sido criticados por terem-se tornado normativos ao invés de descritivos e por ignorar o viés cultural e o evidente conjunto de valores presentes no construto, que faz com que certos traços sejam considerados como positivos e outros como negativos. (YEE, 2005) 
Uma série de estudos empíricos critica, ainda, a descrição parcial da complexidade da estrutura da personalidade humana provida pelos instrumentos e escalas que se baseiam nos Big Five. (ALUJA; GARCIA; GARCIA, 2004; SHAFER, 2001; SCHMITT; BUSS, 2000)

Os estudos e argumentos acima apresentados dão visibilidade ao debate de ideias entre autores, na esfera internacional, evidenciando divergências quanto aos objetivos do instrumento e à fundamentação teórica, epistemológica e metodológica dos procedimentos. Longe de representar o consenso na comunidade científica, os instrumentos derivados do construto Big Five, são amplamente questionados. Essas divergências, no entanto, não são trazidas para o debate no projeto elaborado no Brasil. Isso nos leva a voltar o olhar para algumas especificidades da proposta no âmbito nacional.

\section{Objetivos, pressupostos e resultados do Projeto SENNA: pontuando controvérsias}

O Projeto SENNA se sustenta na ideia de que

[...] competências e habilidades como perseverança, autonomia e curiosidade, são tão importantes quanto as habilidades cognitivas (medidas por testes de desempenho e QI) para a obtenção de bons resultados em diversas esferas do bem-estar individual e coletivo, como educação, renda e saúde. Mais que isso: as evidências sugerem que essas habilidades beneficiam os resultados na vida adulta via escolarização, ou seja, por meio da sua contribuição para o sucesso escolar. (SANTOS; PRIMI, 2014, p. 5)

No que concerne às relaçóes entre habilidades cognitivas e competências socioemocionais, é intrigante que, sem maiores consideraçóes, os proponentes do instrumento, embora reconhecendo a relevância de ambas, enfatizem a separação das mesmas, em tempos em que os esforços de reconceitualização de tais aspectos permeiam vários campos de estudo na busca de superação das dicotomias historicamente estabelecidas (razão/sensibilidade, cognição/emoção, corpo/ mente). Dentre os autores cujas contribuiçóes se destacam sobre o estatuto das emoçóes no desenvolvimento humano e no conhecimento, podemos mencionar, por exemplo: C. Lutz (1988) e D. Le Breton (2009), na antropologia; N. Elias (1994), Reddy (2001) e B. Rimé (2005), na sociologia; H. Maturana (1998) e G. Edelman (1992), no campo da biologia; A. Damásio (1996, 2004) no campo da neurologia. No âmbito da psicologia os trabalhos de H. Wallon e L. Vigotski, já 
nas primeiras décadas do século XX, apontavam nessa direção, sustentados por hipóteses plausíveis, estudos empíricos e argumentação consistente.

Um trabalho que tem tido grande destaque, repercutindo amplamente na produção acadêmica em nosso país, é a denominada Inteligência Emocional e a proposta de alfabetização emocional de D. Goleman (2005). Sua proposta, na qual se pode observar vários pontos de coincidência com o Projeto SENNA, tematiza, por exemplo, a agressão, no tópico intitulado "domando a agressão" de garotos que são considerados como "visivelmente perturbados" e portadores de "distorçôes perceptivas" que surgem já na infância e determinam sua ação na vida adulta: "[...] protótipo do caminho para a violência e a criminalidade começa com crianças agressivas e difíceis de lidar na primeira e segunda séries [...].”. (GOLEMAN, 2005, p. 88) Em meio a inúmeras referências a estudos e programas, o autor ressalta a necessidade de uma "alfabetização emocional". Nos programas que servem de modelo para o ensino da "inteligência emocional”, entre os tópicos que são ensinados, encontram-se a autoconsciência e o controle das emoçóes em atividades que compreendem tarefas como a leitura de emoções em expressóes faciais para controle de impulsos e a identificação de sentimentos a partir de fotos de rostos exibindo uma das chamadas emoçôes básicas - alegria, tristeza, ira, surpresa, medo e nojo. É interessante assinalar aqui, a proximidade das atividades propostas por Goleman com as exemplificadas no relatório da proposta de desenvolvimento de competências soioemocionais.

Na esfera da educação, temos encontrado, sobretudo na última década, diversos trabalhos que enfocam a afetividade em diferentes situaçóes de ensino, procurando salientar a dimensão afetiva na relação professor-aluno e nos processos de aprendizagem. (ARANTES, 2003; LEITE, 2006; TASSONI, 2008) No âmbito dos Estudos da Linguagem, o assunto também tem sido objeto de investigaçôes sistemáticas, nas quais se destacam as marcas das emoçôes no discurso (MACHADO; MENEZES; MENDES, 2007) e se ressaltam o discurso emotivo nas relações professor-aluno-conhecimento. (BARBOSA, 2010)

De maneira geral, os trabalhos mencionados, apesar de alguns pontos controversos, trazem como consistente contribuição o fato de considerarem afeto e cognição como profundamente interrelacionados nos processos de desenvolvimento e aprendizagem humanos.

A compreensão do desenvolvimento como multidimensional não implica, portanto, as múltiplas dimensões como aspectos separados. Pelo contrário, se as características ou atributos específicos podem ser discretizados na e pela língua, isso não quer dizer que eles sejam mensuráveis isoladamente, mas que merecem ser considerados em sua dinâmica complexidade. Crianças podem ser muito persistentes em certas situaçóes e pouco persistentes em outras. Alguns sujeitos serão extremamente atentos e interessados em certas atividades e não em 
outras. Algumas atividades serão capazes de despertar a criatividade em alunos de diferentes idades, em diferentes contextos. Jovens podem ser muito perseverantes em relação a certos objetivos e pouco perseverantes quando esses objetivos não são genuinamente apropriados por eles. $\mathrm{O}$ mesmo se aplica à criatividade, curiosidade, disciplina e outros atributos, e se torna especialmente relevante quando se pensa na escola, com a suas demandas e regras de participação, muitas vezes distantes dos valores que regem as comunidades de origem dos alunos. $\mathrm{O}$ desmembramento das dimensóes da personalidade em competências não cognitivas induz à concepção de que tais dimensôes são independentes do contexto, do conteúdo e do significado da atividade ou da situação em que se manifestam.

$\mathrm{Na}$ justificativa do estudo, os proponentes afirmam que

[...] a escola reconhece a importância dessa abordagem, entendendo que o desenvolvimento dos alunos é multidimensional e que o aprendizado envolve o domínio de competências 'não cognitivas', de natureza afetiva e comportamental [...]. (SANTOS; PRIMI, 2014, p. 11)

De fato, se a escola, ou os profissionais da educação não só reconhecem mas relevam a dimensão afetivo-emocional do desenvolvimento humano, isso não significa reconhecer a importância de uma única abordagem, nem significa assumir tal dimensão em termos de "competências não cognitivas".

Como podemos constatar, há uma extensa e heterogênea produção, que tem repercutido, de maneiras diversas, na formulação de políticas públicas, proporcionando subsídios para a elaboração e implementação de propostas curriculares e programas de ensino em diferentes redes estaduais e municipais do país.

O Relatório afirma, ainda, que

[...] apesar do reconhecimento devotado à esfera socioemocional por pais e professores, pouco esforço é dedicado ao seu desenvolvimento intencional e à avaliaçáo da efetividade das intervençóes que se destinam a promovê-lo. Entre as principais causas dessa limitação está a falta de conhecimentos a respeito dos mecanismos pelos quais essas competências podem ser desenvolvidas e medidas nos diversos contextos de aprendizagem, sendo que parte dessa limitação é derivada da relativa escassez de estudos que investigam a relação entre características socioemocionais e variáveis relacionadas ao aprendizado. Essa escassez de estudos, por sua vez, é em grande medida resultante da falta de bases de dados que simultaneamente contêm informaçóes dessa natureza e variáveis de resultado de aprendizado. (SANTOS; PRIMI, 2014, p. 11) 
Deparamo-nos aqui com argumentos e generalizaçôes que também se tornam pontos controversiais. Ao afirmarem que "[...] pouco esforço é devotado a seu desenvolvimento intencional e à avaliação da efetividade das intervençóes [...]", e ao referirem "[...] à falta de conhecimentos a respeito dos mecanismos pelos quais essas competências podem ser desenvolvidas e medidas [...]”, os autores, além de colocarem como parâmetro de avaliação um único modelo que privilegia determinadas competências mensuráveis isoladamente, menosprezam o trabalho efetivo realizado por milhares de professores no cotidiano das escolas e no enfrentamento de situaçóes de ensino que articulam aspectos cognitivos e afetivos levando em conta condiçóes concretas, dentre essas, a precariedade, muitas vezes, extrema, das condiçóes de vida e das condiçóes de ensino. Ao referirem à relativa escassez de estudos, os autores posicionam-se na defesa de um ponto de vista, o qual apresentam sem discussão, desconsiderando tanto os debates e as polêmicas, como uma extensa produção nacional e internacional, sobre o assunto.

Santos e Primi (2014), autores do Relatório supracitado, dizem ainda que "evidências sugerem" que "resultados na vida adulta" - aqui implícitos emprego e renda - estão ligados ao sucesso/desempenho escolar. E nesse sentido, ressaltam o objetivo de "[...] quantificar a importância relativa de atributos socioemocionais vis-à-vis outros determinantes do desempenho escolar [...]”, pretendendo “[...] saber quanto das diferenças de desempenho observadas entre os estudantes está associada a diferentes conjuntos de características individuais e familiares."

O que parece sustentar esse objetivo é a suposição de que quantificar atributos e estabelecer correlaçóes levaria a um mapeamento de casos e situaçóes que permitiria não só constatar, mas intervir no processo de escolarização.

No entanto, apesar do valor heurístico dos estudos que utilizam a análise fatorial para a pesquisa sobre a personalidade humana, a quantificação proposta sobre bases tão frágeis, no caso concreto que nos ocupa, corre o risco de gerar perfis não apenas questionáveis do ponto de vista científico, como também potencialmente estigmatizadores para alunos que já enfrentam inúmeras dificuldades nas suas trajetórias escolares e condiçóes de vida. Cabe, então, perguntar a que levaria, nesse contexto, estabelecer correlaçóes e associaçóes entre o desempenho dos estudantes e as suas características individuais e familiares. Ao estabelecimento de certas normas de conduta? À standartização das competências? A mudanças no trabalho pedagógico? À transformação nas condiçóes de trabalho e de vida? Tudo indica, no entanto, que muito mais do que transformar as precárias condiçóes, espera-se, sim, que os alunos desenvolvam as competências e habilidades que os tornem bem sucedidos independentemente das suas condiçóes concretas de vida.

A orientação do projeto e o caráter especulativo do exercício estatístico se revelam mais claramente no seguinte trecho: 
Para ilustrar, observamos no Gráfico 5 que o impacto de Conscienciosidade sobre o desempenho de matemática é 4,5. Isso significa que, se elevarmos a conscienciosidade de um estudante que hoje está entre os que possuem menor nível desse atributo (isto é, um estudante no percentil 25), até que ele esteja entre os que possuem maior nível do mesmo (alguém no percentil 75), o desempenho desse estudante subiria o equivalente a 4,5 meses de aprendizado. (SANTOS; PRIMI, 2014, p. 63)

Embora seja provável que esses atributos influenciem de fato o desempenho, inclusive porque a escola valoriza os atributos da conscienciosidade (disciplina, organização etc.), o exemplo citado, que ilustra a lógica interna do estudo, conduz a pensar as relaçóes de ensino-aprendizagem como relaçóes causais, diretas, que reduzem e atomizam o desenvolvimento.

\section{A proposta SENNA: política pública?}

Face, portanto, às controvérsias relacionadas aos fundamentos epistemológicos do construto Big five e aos questionamentos levantados sobre a pertinência de se utilizar a análise fatorial como base para o estudo da personalidade; face à dificuldade de operar com as relaçóes entre os aspectos sociais e individuais da personalidade humana e à existência de inúmeras teorias que argumentam em favor de uma complexidade irredutível a uns poucos traços; diante, ainda, das polêmicas conceituais e metodológicas implicadas na separação das dimensôes cognitiva e emocional e dos problemas na modelização de suas mútuas influências e inter-relaçóes; posicionamo-nos contra a adoção e implementação de tal proposta como política pública.

Os questionamentos evidenciam que por trás da aparente pertinência e simplicidade do modelo, escondem-se problemas de várias ordens. Os argumentos levantados pelos proponentes a respeito da conveniência dos procedimentos e do instrumento de avaliação - "economicamente viável para aplicação em larga escala"; "cientificamente robusto para subsidiar pesquisas acadêmicas na área"; "visão rigorosa" dos estudos e "impacto positivo comprovado pela evidência científica" - ficam, desse modo, extremamente fragilizados.

Separar, para fins de mensuração, os aspectos socioemocionais dos aspectos cognitivos, isolando habilidades e traços de personalidade pré-definidos a partir de um construto tão questionado, tende a congelar e tipificar comportamentos, estabelecendo correlaçóes que, mais uma vez, simplificam a complexidade e a dinâmica do desenvolvimento humano e ocultam as condiçóes e contradiçóes vivenciadas e enfrentadas por professores, alunos e seus familiares no cotidiano da instituição escolar. 
Assim sendo, os resultados de tal avaliação podem, inclusive, produzir efeitos contrários aos proclamados pelos proponentes do instrumento, amplificando os riscos de estigmatização de alunos cujas competências não correspondam às previamente estipuladas. Diante da imprecisão das categorias e da decorrente parcialidade dos resultados e diagnósticos, os impactos da medição na intervenção pedagógica tornam-se problemáticos e as anunciadas contribuiçóes à educação pública tornam-se discutíveis.

Desse modo, assumir essa proposta de avaliação - Social and Emotional Non-cognitive Nationwide Assessment - como política pública parece ser, no mínimo, temerário. E pontuando aqui mais uma controvérsia, referimos às politicas de avaliação de larga escala (PATTO, 1997; FREITAS, 2002, 2004, 2014; RAVITCH, 2011), cujas dimensóes econômico-financeiras tem sido objeto de fortes críticas e acirradas disputas. A indagação que persiste após a análise do documento é: o que, de fato, se avalia, porque e para que, quando se aplica tal instrumento de "medida socioemocional" em larga escala?

\section{Referências}

ADLER, A. A ciência da natureza humana. 6. ed. São Paulo: Nacional, 1967. . A educação das crianças. Salvador: Arte em Palavras, 2003.

ALLPORT, G. W. Personality. A psychological interpretation. New York: Henry Holt and Company, 1937. . Letters from Jenny. New York: Harcourt, Brace \& World Inc., 1965.

ALLPORT, G. W.; ODBERT, H. S. Trait-names: A psycho-lexical study. Psychological Monographs, v. 47, n. 1, p. 01-171, 1936.

ALUJA, A.; GARCIA, O.; GARCIA, L. F. Replicability of the three, four and five Zuckerman's personality super-factors: Exploratory and confirmatory factor analysis of the EPQ-RS, ZKPQ and NEO-PI-R. Personality and Individual Differences, v. 36, p.10931108, 2004.

ARANTES, V. A. Afetividade na escola. São Paulo: Summus, 2003.

BANDURA, A. Apresentação. Disponível em: https://psychology.stanford.edu/abandura. Acesso em: 12 dez. 2014.

BANDURA, A.; AZZI, R.; POLYDORO, S. Teoria Social Cognitiva: conceitos básicos. Porto Alegre: Artmed, 2008.

BARBOSA, M.V. O discurso emotivo nas interaçôes em sala de aula. São Paulo: Annablume, 2010.

BLOCK, J. A contrarian view of the five-factor approach to personality description. Psychological Bulletin, v.117, p.187-229, 1995a. 
BLOCK, J. A. Going beyond the five factors given: Rejoinder to Costa and McCrae and Goldberg and Saucier. Psychological Bulletin, v. 117, p. 226-229, 1995 b.

. Millenial contrarianism: The five factor approach to personality description 5 years later. Journal of Research in Personality, v.35, p.98-107, 2001.

. The Five Factor Framing of personality and beyond: some ruminations. Psychological Inquiry, v. 21, p. 2-25, 2010.

BOYLE, G. J. Crisis in traditional personality assessment: Implications for military testing. In.: PROCEEDINGS OF THE 39TH ANNUAL CONFERENCE OF THE INTERNATIONAL MILITARY TESTING ASSOCIATION, Sydney, 1997, p.14-16.

. Critique of the five-factor model of personality. Humanities \& Social Sciences papers. Paper 297, 2008. Disponível em: <http://epublications.bond.edu.au/hsspubs/297>. Acesso em: 4 mar. 2015.

BRIGGS, S. R. Assessing the five-factor model of personality description. Journal of Personality, v. 60, p. 253-293, 1992.

CATTELL, R. B. Description and measurement of personality. Oxford, England: World Book Company, 1946.

Books, 1965.

. The scientific analysis of personality. Harmondsworth, Mddx., England: Penguin

CATTELL, R. B.; BOYLE, G. J.; CHANT, D. Enriched behavioral prediction equation and its impact on structured learning and the dynamic calculus. Psychological Review, v. 109, n. 27, p. 202-205, 2002.

CLACSO. Políticas educativas y derecho a la educación en América Latina y el Caribe. Declaración del Grupo de Trabajo, Conselho Latino-Americano de Ciências Sociais, 2014. Disponível em: <http://www. clacso.org.ar/difusion/Declaracion_GT_politicas_educativas/Declaracion_GT_Politicas_educativas_y_derecho_a_la_educacion_en_America_Latina_y_El_Caribe.pdf $>$. Acesso em: 12 fev. 2015.

COSTA, P. T. Jr.; McRAE, R. R. Revised NEO Personality Inventory (NEO-PI-R) and NEO Five-Factor Inventory (NEO-FFI) professional manual. Odessa, FL: Psychological Assessment Resources, Inc., 1992.

DAMÁSIO, A. O Erro de Descartes - Emoção, Razão e Cérebro Humano. São Paulo: Companhia das Letras, 1996.

. Em busca de Espinosa: prazer e dor na ciência dos sentimentos. São Paulo: Companhia das Letras, 2004.

DAINEZ, D.; SMOLKA, A.L.B. O conceito de compensação no diálogo de Vigotski com Adler: desenvolvimento humano, educação e deficiência. Revista Educação e Pesquisa, São Paulo, v. 40, n. 4, p.1093-1108, 2014.

DAVIES, B.; HARRÉ, R. Positioning: the discursive production of selves. Journal for the Theory of Social Behaviour, v. 20, n. 1, p. 43-63, 1990. 
EDELMAN, G. M. Biologia da consciência - As raizes do pensamento [Biology of consciousness - The roots of thought]. Lisbon, Portugal: Inst. Piaget, 1992.

ELIAS, N. A sociedade dos indivíduos. Rio de Janeiro: Zahar, 1994.

ERIKSON, E.H. Infância e sociedade. 2. ed. Rio de Janeiro: Zahar, 1976a. . Identidade: Juventude e crise. 2.ed. Rio de Janeiro: Zahar, $1976 \mathrm{~b}$.

EYSENCK, H. J. The structure of personality. London: Methuen, 1970.

. Four ways five factors are not basic. Personality and Individual Differences, v. 13, p. 667-673, 1992.

. Comment on Goldberg. American Psychologist, v.48, p. 1299-1300, 1993.

. Personality and experimental psychology: the unification of psychology and the possibility of a paradigm. Journal of Personality and Social Psychology, v. 73, p. 1224-1237, 1997.

FRALEY, R. C.; ROBERTS, B. W. Patterns of continuity: a dynamic model for conceptualizing the stability of individual differences in psychological constructs across the life course. Psychological Review, v. 112, p. 60-74, 2005.

FREITAS, L. C. Avaliação: construindo o campo e a crítica. Florianópolis: Insular, 2002.

A avaliação e as reformas dos anos 1990: novas formas de exclusão, velhas formas de subordinação. Educação e Sociedade, Campinas, v. 25, n. 86, p. 133-170, 2004.

. Avaliação e Políticas Públicas Educacionais. Ensaios contraregulatórios em debate. Campinas, SP: Leitura Crítica, 2014.

FREUD, S. A Psicologia das Massas e Análise do Eu. São Paulo: L\&PM Pocket, 1921/2013. . O ego e o id e outros trabalhos. Obras Completas, Rio de Janeiro: Imago, v. 19., $1923 / 2006$.

. O mal-estar na civilização. São Paulo: Imago, v.21, 1930/1992.

FROMM, E. Análise do homem. 2. ed. Rio de Janeiro: Zahar, 1961.

. Psicanálise da sociedade contemporânea. 3. ed. Rio de Janeiro: Zahar, 1963.

. Meu encontro com Marx e Freud. 4. ed. Rio de Janeiro: Zahar, 1967.

. O medo à liberdade. 7. ed. Rio de Janeiro: Zahar, 1970.

GOFFMAN, E. A Representação do Eu na vida cotidiana. Rio de Janeiro: Vozes, 1959/1985. . Estigma. Notas sobre a manipulação da identidade deteriorada. 4. ed. Rio de Janeiro: Guanabara, 1963/1988.

GOLDBERG, L. R. The structure of phenotypic personality traits. American Psychologist, v. 48, p. 26-34, 1993.

GOLEMAN, D. Inteligência Emocional. Rio de Janeiro: Objetiva, 2005. 
HARRÉ, R. Positioning Theory. 2004. Disponível em <www.massey.ac.nz/alock/virtual/ positioning.doc>. Acesso em: 12 fev. 2015.

HELSON, R. et. al. The growing evidence for personality change in adulthood: findings from research with personality inventories. Journal of Research in Personality. v. 36, n.4, p. 287-306, 2002.

HERMANS, H.; HERMANS-KONOPKA, A. Dialogical Self Theory. Positioning and Counter-positioning in a Globalizing Society. New York, Cambridge University Press, 2010.

JANG, K. L. et. al. Genetic and environmental influences on the covariance of facets defining the domains of the five factor model of personality. Personality and Individual Differences, v. 33, p. 83-101, 2002.

LAPLANCHE, J. Vocabulário de Psicanálise. São Paulo: Martins Fontes, 4a ed. 2001.

LE BRETON, D. As paixôes ordinárias: antropologia das emoções. Petrópolis: Vozes, 2009 .

LEITE, S. A. Afetividade e práticas pedagógicas. São Paulo: Casa do psicólogo, 2006.

LEONTIEV, A. N. Activité, conscience, personnalité. Moscou: Editions du Progrès, 1984.

. Uma contribuição à teoria do desenvolvimento da psique infantil. In: VIGOTS-

KI, L.S.; LURIA, A.R.; LEONTIEV, A. N. Linguagem, desenvolvimento e aprendizagem. São Paulo: Ícone, 1988, p. 59-83.

LUTZ, C. Unnatural emotions: everyday sentiments on a Micronesian atoll and their challenge to Western theory. Chicago: University of Chicago Press, 1988.

MACHADO, I. L.; MENEZES, W.; MENDES, E. As emoçóes no discurso. Rio de Janeiro: Lucerna, 2007.

MATURANA, H. Emoções e Linguagem na Educação e na Política. Belo Horizonte: Editora UFMG, 1998.

McADAMS, D. P. The five-factor model in personality: a critical appraisal. Journal of Personality, v. 60, p.329-361, 1992.

McCRAE, R. R. et. al. Nature over nurture: temperament, personality, and life span development. Journal of Personality and Social Psychology, v. 78, p. 173-186, 2000.

McCRAE, R. R.; COSTA, P. T. Rotation to maximize the construct validity of factors in the NEO Personality Inventory. Multivariate Behavioral Research, v. 24, p. 107-124, 1989.

MEAD, G. Mind, self and society. Chicago: Chicago University Press, 1934/1962.

PATTO, M.H.S. Para uma crítica da razão psicométrica. Psicol. USP, v. 8, n. 1, São Paulo, p. 47-62, 1997. Disponível em <http://dx.doi.org/10.1590/S0103-65641997000100004>. Acesso em: 12 dez. 2014.

PERVIN, L. A. A critical analysis of current trait theory. Psychological Inquiry, v. 5, p. 103-113, 1994. 
RAVITCH, D. The death and life of the great American School System. How testing and choice are undermining education. New York: Basic Books, 2011.

REDDY, W. The Navigation of Feeling: A Framework for the History of Emotions. Cambridge: Cambridge University Press, 2001.

RIMÉ, B. Le partage social des émotions. Paris: Presses Universitaires de France, 2005.

ROBERTS, B. W.; WALTON, K. E.; VIECHTBAUER, W. Patterns of mean-level change in personality traits across the life course: A meta-analysis of longitudinal studies. Psychological Bulletin, v. 132, p. 1-25, 2006a.

. Personality traits change in adulthood: Reply to Costa and McCrae. Psychological Bulletin, v. 132, p.29-32, 2006b.

ROCHEX, J. Y. PISA et les enquêtes internationales. Enjeux scientifiques, enjeux politiques. Revue française de pédagogie. Évaluation des politiques éducatives et comparaisons internationals, v. 164, 2008. Disponível em: http://rfp.revues.org/2135. Acesso em: 14 dez. 2014.

. PISA: Viser le noyau dur de la construction des inégalités scolaires. L’Expresso. Café Pedagogique, 2012. Disponível em: http://www.cafepedagogique.net/LEXPRESSO/ Pages/2013/12/06122013Article635219127274452419.aspx. Acesso em: 14 dez.2014.

ROGERS, C. Tornar-se pessoa. São Paulo: Martins Fontes, 1961/1976.

ROMNEY, D. M.; BYNNER, J. M. The structure of personal characteristics. Westport, CT: Praeger, 1992.

SANTOS, D.; PRIMI, R. Desenvolvimento socioemocional e aprendizado escolar: uma proposta de mensuração para apoiar políticas públicas. Relatório sobre resultados preliminares do projeto de medição de competências socioemocionais no Rio de Janeiro, São Paulo: OCDE, SEEDUC, Instituto Ayrton Senna, 2014.

SCHMITT, D. P.; BUSS, D. M. Sexual dimensions of person description: Beyond or subsumed by the Big Five?. Journal of Research in Personality, v. 34, p. 141- 177, 2000.

SHAFER, A. B. The Big Five and sexuality trait terms as predictors of relationships and sex. Journal of Research in Personality, v. 35, p. 313-338, 2001.

SOLDZ, S.; VAILLANT, G. E. The Big Five personality traits and the life course: A 45year longitudinal study. Journal of Research in Personality, v. 33, p. 208-232, 1999.

TASSONI, E.C. A dinâmica interativa na sala de aula: as manifestaçôes afetivas no processo de escolarização. 2008. Tese (Doutorado em Educação) - Faculdade de Educação. Universidade Estadual de Campinas, Campinas. 2008.

TOOMELA, A. Relationships between personality structure, structure of word meaning, and cognitive ability: A study of cultural mechanisms of personality. Journal of Personality and Social Psychology, v. 85, p. 723-735, 2003. 
VIGOTSKI, L. S. Sobre a questão da dinâmica do caráter infantil. (Tradução Zoia Prestes) Linhas Críticas, Brasília, v. 12, n. 23, 2006. Disponível em: <http://seer.bce.unb.br./index. php/linhascriticas/article/view/1615>. Acesso em: 10 jun. 2011. 2000. . Manuscrito de 1929. Educação \& Sociedade, Campinas, ano 21, n.71, p.21-44, . Psicología infantil (incluye Paidología del adolescente, problemas de la psicología infantil). Obras Escogidas, v. 4. Madrid: Visor Distribuiciones, S.A., 1996.

. Problemas del desarrollo de la psique. Obras Escogidas, v. 3. Madrid: Visor Distribuiciones, S.A., 1995.

VIGOTSKII, L. S.; LURIA, A. R.; LEONTIEV, A. N. Linguagem, desenvolvimento e aprendizagem. São Paulo: Ícone, 1988.

ZUCKERMAN, M. Personality Questionnaire (ZKPQ): an alternative five factorial model. In.: ZUCKERMAN, M.; De RAAD, B.; PERUGINI, M. Big five assessment. Hogrefe ET Huber Publishers, 2002, p. 377-396.

YEE. Hidden agenda: what do personality trait assessments really assess? Disponível em: http://www.nickyee.com/ponder/big5.html. Acesso em: 10 de novembro de 2014.

WALLON, H. Do Acto ao Pensamento. Lisboa: Moraes, 1979. . As origens do caráter na criança. São Paulo: Nova Alexandria, 1934/1995.

Recebido em 23 de maio de 2015.

Aprovado em 26 de maio de 2015. 